\title{
Bardet-Biedl Syndrome with Familial Retinitis Pigmentosa - A Case Report
}

\author{
Gaurav Paranjpe ${ }^{1}$, Neha Shetty ${ }^{2}$
}

1, 2 Department of Ophthalmology, Krishna Institute of Medical Sciences, Karad, Maharashtra, India.

\section{INTRODUCTION}

Moon along with Laurence in 1866 documented a family of four siblings with obesity, spastic paraparesis, retinal dystrophy, and cognitive deficit. ${ }^{1}$ Biedl $^{2}$ and Bardet $^{3}$ separately described later on people with similar features along with post-axial polydactyl and the syndrome was termed Laurence-Moon-Bardet-Biedl syndrome. ${ }^{4}$ Five cardinal features of Bardet-Biedl syndrome (BBS) include polydactyly, pigmentary retinopathy, obesity, mental retardation and hypogonadism. Its prevalence is 1:13,500 in Kuwait. ${ }^{5}$ Larger incidence in Arabic communities can be due to high rate of consanguineous marriages. ${ }^{6}$ Less than 15 cases have been reported from India. ${ }^{7}$

Bardet-Biedl syndrome is a disorder of immotile cilia. Motile cilia generate movement of fluid and immotile cilia are sensory organelles defects which cause polydactyly, learning difficulties, retinitis pigmentosa, situs inversus, and cyst formation in pancreas, kidneys and liver.

The Bardet-Biedl syndrome is an infrequent autosomal recessive ciliopathic, pleiotropic disorder. It includes retinitis pigmentosa, obesity, polydactyly, learning disabilities and hypogonadism. This is a case series of a family with five out of eight siblings showing all ocular features and most of general features of Bardet-Biedl syndrome fulfilling the diagnostic criteria.

Diagnostic Criteria of the syndrome is enlisted below (Table 1). Presence of 4 major signs or 2 minor plus 3 major signs diagnoses this syndrome.

\begin{tabular}{|cc|}
\hline Major Features & Minor Features \\
Polydactyly & Learning difficulties \\
Retinal dystrophy & Diabetes mellitus \\
Central obesity & Development delay \\
Renal abnormalities & Facial dysmorphism \\
Hypogenitalism in men & Neurological deficits \\
& Hypertension \\
\hline Table 1. Diagnostic Criteria for BBS (Major and Minor Features) \\
\hline
\end{tabular}

\section{PRESENTATION OF CASE}

We report a series of five cases, five out of eight siblings fulfilling the diagnostic criteria for Bardet-Biedl syndrome. They were off springs of a second-degree consanguineous marriage.

\section{Case 1}

A 31-year-old man presented with a complaint of loss of vision in both eyes since childhood. He had diminution of vision in both eyes which progressed to blindness by the age of 8 years. He was the first among the eight siblings. He was mentally challenged. General examination showed polydactyl in all the limbs. The patient had a body-mass index (BMI) of 31.1. He had hypogonadism. He suffered from chronic kidney disease and was on haemodialysis. (Figure 1)
Corresponding Author:

Dr. Neha Shetty,

A Wing Second Floor, Flat No. 24,

Shri Gajanan Building, Opposite Gupte

Maternity Home, Dilip Gupte Road,

Mahim (W), Mumbai-16,

Maharashtra, India.

E-mail: nehashetty94@gmail.com

DOI: $10.14260 /$ jemds/2021/12

How to Cite This Article:

Paranjpe G, Shetty N. Bardet-biedl syndrome with familial retinitis pigmentosa - a case report.J Evolution Med Dent Sci 2021;10(01):62-64, DOI: 10.14260/jemds/2021/12

Submission 16-09-2020,

Peer Review 10-11-2020,

Acceptance 16-11-2020,

Published 04-01-2021.

Copyright (c) 2021 Gaurav Paranjpe et al. This is an open access article distributed under Creative Commons Attribution License [Attribution 4.0 International (CC BY 4.0)] 


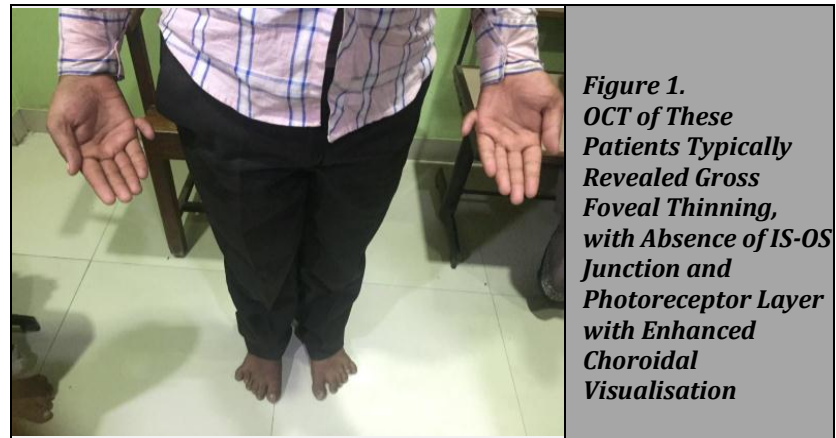

Both eyes had no PL (Perception of Light). Intraocular pressures (IOP) was 24 and $25 \mathrm{~mm}$ of $\mathrm{Hg}$ in right and left eye respectively. He had posterior subcapsular cataract in both eyes. On fundus examination a waxy pale disc, attenuation of arteries, tessellated background and bony spicules in the periphery, were seen suggestive of retinitis pigmentosa with optic atrophy bilaterally.

\section{Case 2}

26-year-old woman came complaining of blurring of vision at night since childhood which has slowly progressed to diminished vision even during the daytime. She is the third among the 8 siblings. She was mentally challenged. General examination showed polydactyl in both upper limbs. She had a BMI of 33.1. At presentation her vision was hand movements close to face in both her eyes. IOP measured $22 \mathrm{~mm}$ of $\mathrm{Hg}$ bilaterally. Anterior segment findings on slit lamp examination were normal. Fundi of both eyes showed typical features of retinitis pigments with characteristic optical coherence tomography (OCT) pattern of foveal thinning, with absence of inner and outer segment junction (IS-OS) with enhanced choroidal visualisation.

\section{Case 3}

22-year-old man came complaining of blurring of vision in both eyes since childhood especially in the night, which progressed gradually over the years. He is the 4 th among the 8 siblings. General examination showed polydactyly in upper 2 and right lower limb. Patient had a BMI of 29.1. He had hypogonadism. He is a diagnosed case of chronic renal disease under treatment. Visual acuity was hand movements near to face bilaterally. His IOP taken was 18 and $20 \mathrm{~mm}$ of $\mathrm{Hg}$ in right eye and left eye respectively. Anterior segment had early posterior subcapsular cataract in both eyes. Fundi of both eyes showed a waxy pale optic disc and pigmentation in the retinal periphery consistent with retinitis pigmentosa.

\section{Case 4}

An 18-year-old woman came with diminution of vision bilaterally. She's is the $6^{\text {th }}$ among the 8 siblings. She was mentally challenged. General examination revealed polydactyly in left upper limb. Her BMI was 33.6. Her vision was hand movements close to face in her right eye and finger counting at 1 metre in her left eye. IOP was 18 and $19 \mathrm{~mm}$ of $\mathrm{Hg}$ in right and left respectively. Case presented with posterior subcapsular cataract bilaterally and fundi of both eyes showed findings suggestive of retinitis pigmentosa.

\section{Case 5}

A 14-year-old boy, $8^{\text {th }}$ offspring of the family, presented with complains of diminution of vision in both eyes since childhood which is gradual and progressive in nature. The boy was mentally challenged. General examination revealed polydactyly in upper limbs and BMI -29.4. His vision was counting fingers and hand movements in both eyes. Intraocular tension was $12 \mathrm{~mm}$ of $\mathrm{Hg}$ in right and $11 \mathrm{~mm} \mathrm{Hg}$ in contralateral eye. Anterior segment on slit lamp was normal. Fundus documented retinitis pigmentosa in both eyes.

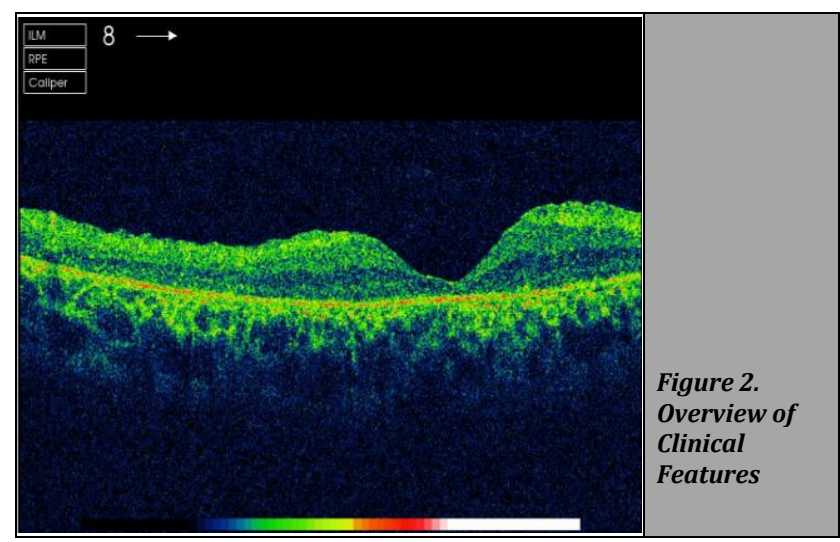

\begin{tabular}{|c|c|c|c|c|c|c|c|c|}
\hline 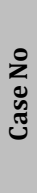 & $\stackrel{\leftrightarrow}{\&}$ & 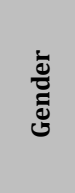 & $\begin{array}{l}\frac{\vec{y}}{8} \\
\frac{0}{0}\end{array}$ & 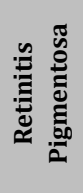 & 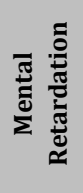 & $\begin{array}{l}\frac{\lambda}{2} \\
\frac{\pi}{0} \\
\frac{\pi}{0} \\
\frac{2}{0} \\
2\end{array}$ & 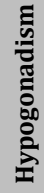 & స⿱艹 \\
\hline 1 & 31 & Male & + & + & + & + & + & + \\
\hline 2 & 26 & $\begin{array}{c}\text { Femal } \\
\mathrm{e}\end{array}$ & + & + & + & + & $\mathrm{x}$ & $\mathrm{x}$ \\
\hline 3 & 22 & Male & + & + & $\mathrm{x}$ & + & + & + \\
\hline 4 & 18 & $\begin{array}{c}\text { Femal } \\
\mathrm{e}\end{array}$ & + & + & + & + & $\mathrm{x}$ & $\mathrm{x}$ \\
\hline 5 & 14 & Male & + & + & + & + & + & $\mathrm{x}-$ \\
\hline \multicolumn{9}{|c|}{$\begin{array}{l}\text { Table 2. All Five Patients were Diagnosed with } \\
\text { ll-Bardet Syndrome Based on the Diagnostic Criteria }\end{array}$} \\
\hline
\end{tabular}

\section{DISCUSSION}

Bardet-Biedl syndrome is a pleiotropic inherited disorder with notable interfamilial and intrafamilial variation. ${ }^{8,9}$ The disease does not have any known modifiable or preventive risk factors except avoidance of consanguineous marriage.

Apart from the cardinal manifestations, other features include congenital heart block, brachycephaly, dental anomalies and deafness. Early and prompt recognition is important to help in the treatment of the child through timely assessment of blood pressure, weight, renal imaging and renal function test, ophthalmologic examinations and psychological support although no definitive treatment at present. ${ }^{10}$

Rapid neonatal diagnosis achievable by correlating prenatal detection of polydactyly with sonography along with genetic studies shortly after birth ${ }^{11}$ Nephrologists have a main role in management as renal failure most likely causes death 
among Bardet-Biedl syndrome patients. ${ }^{12}$ Testosterone supplements may be given to male sufferers, specifically in cases having lowered level of this hormone.13

Accessory fingers and toes are often non-functional and can be excised. Obesity is a major worrisome area as, if left uncontrolled, will lead to multiple health problems. A lowprotein and low-calorie diet helps to combat obesity and slows the progression of renal failure.

There are no documented effective treatments to either avoid or reduce the deterioration in vision. However, low vision aids can be helpful to the patient, and regular ophthalmological follow-up is stressed upon.

The detrimental effects of consanguineous marriage cannot be overlooked. In many communities, in whom the frequency of consanguinity in marriages is large, there is an associated low genetic literacy level among the public so the need for education is very important for them.

The offspring of consanguineous unions may have a high chance to present with recessive disorders due to the appearance of recessive genetic mutations received from a common ancestor. The nearer a genetic association of parents, more is the chance their child will inherit similar copies of detrimental recessive genes. ${ }^{14}$

\section{CONCLUSIONS}

In such societies, wherein in the rate of consanguineous marriages is very large are mostly poor in genetic knowledge among the general public including the health care personnel. So, the requirement for education is of utmost need. Premarital and preconception genetic counselling is essential in populations wherein consanguineous marriage is still practiced and abortion of the affected fetus is not accepted by the community. This is the largest number of cases reported of Bardet-Biedl syndrome in a family.

Financial or other competing interests: None.

Disclosure forms provided by the authors are available with the full text of this article at jemds.com.

\section{REFERENCES}

[1] Laurence JZ, Moon RC. Four cases of retinitis pigmentosa occurring in the same family and accompanied by general imperfections of development. Ophthal Rev 1866;2:3241.

[2] Biedl A. A pair of siblings with adiposo-genital dystrophy 1922. Obes Res 1995;3(4):404.

[3] Bardet G. On congenital obesity syndrome with polydactyly and retinitis pigmentosa (a contribution to the study of clinical forms of hypophyseal obesity) 1920. Obes Res 1995;3(4):387-99.

[4] Solis-Cohen S, Weiss E. Dystrophia adiposogenitalis, with atypical retinitis pigmentosa and mental deficiency-the Laurence-Biedl syndrome: a report of four cases in one family. Am J Med Sci 1925;169:489-505.

[5] Forsythe E, Beales PL. Bardet-Biedl syndrome. Eur J Hum Genet 2013;21(1):8-13.

[6] Farag TI, Teebi AS. High incidence of Bardet Biedl syndrome among the Bedouin. Clin Genet 1989;36(6):463-4.

[7] Hooda AK, Karan SC, Bishnoi JS, et al. Renal transplant in a child with Bardet - Biedl syndrome: a rare cause of endstage renal disease. Indian J Nephrol 2009;19(3):112-4.

[8] Prosperi L, Cordella M, Bernasconi S. Electroretinography and diagnosis of the Laurence Moon-Bardet-Biedl syndrome in childhood. J Pediatr Ophthalmol 1977;14(5):305-8.

[9] Waters AM, Beales PL. Bardet-Biedl syndrome gene reviews 1993-2003. (Updated 2011).

[10] Anjum F, Rahman A, Roy RR. Bardet-Biedl syndrome: a rare report of two sibling affected and third sibling with multiple anomalies. Bangladesh J Child Health 2016;40(1):52-7.

[11] Ashkinadze E, Rosen T, Brooks SS, et al. Combining fetal sonography with genetic and allele pathogenicity studies to secure a neonatal diagnosis of Bardet-Biedl syndrome. Clin Genet 2013;83(6):553-9.

[12] O'Dea D, Parfrey PS, Harnett JD, et al. The importance of renal impairment in the natural history of Bardet- Biedl syndrome. Am J Kidney Dis 1996;27(6):776-83.

[13] Kumar S, Mahajan BB, Mittal J. Bardet-Biedl syndrome: a rare case report from North India. Indian J Dermatol Venereol Leprol 2012;78(2):228.

[14] Shawky RM, Elsayed SM, Zaki ME, et al. Consanguinity and its relevance to clinical genetics. Egyptian Journal of Medical Human Genetics 2013;14(2):157-64. 